\title{
Influence of iridium doping in MgB2 superconducting wires
}

\section{Grivel, Jean-Claude}

\section{Published in:}

Physica C: Superconductivity and its Applications

Link to article, DOI:

10.1016/j.physc.2018.01.002

Publication date:

2018

Document Version

Peer reviewed version

Link back to DTU Orbit

Citation (APA):

Grivel, J-C. (2018). Influence of iridium doping in MgB2 superconducting wires. Physica C: Superconductivity and its Applications, 547, 7-15. https://doi.org/10.1016/j.physc.2018.01.002

\section{General rights}

Copyright and moral rights for the publications made accessible in the public portal are retained by the authors and/or other copyright owners and it is a condition of accessing publications that users recognise and abide by the legal requirements associated with these rights.

- Users may download and print one copy of any publication from the public portal for the purpose of private study or research.

- You may not further distribute the material or use it for any profit-making activity or commercial gain

- You may freely distribute the URL identifying the publication in the public portal

If you believe that this document breaches copyright please contact us providing details, and we will remove access to the work immediately and investigate your claim 


\section{Accepted Manuscript}

Influence of iridium doping in $\mathrm{MgB}_{2}$ superconducting wires

J.-C. Grivel

PII:

S0921-4534(17)30141-7

DOI:

10.1016/j.physc.2018.01.002

Reference:

PHYSC 1253239

$\tan$

V.V. MOSHCHALKOV T. TOHYAMA
X. OBBADORS
S. TAMMUMA WEN

UPERCONDUCTIVITY

AND ITS APPIICATIONS

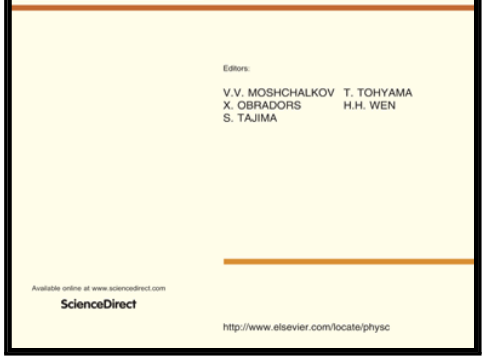

To appear in:

Physica C: Superconductivity and its applications

Received date:

24 April 2017

Revised date:

10 August 2017

Accepted date:

9 January 2018

Please cite this article as: J.-C. Grivel, Influence of iridium doping in $\mathrm{MgB}_{2}$ superconducting wires, Physica C: Superconductivity and its applications (2018), doi: 10.1016/j.physc.2018.01.002

This is a PDF file of an unedited manuscript that has been accepted for publication. As a service to our customers we are providing this early version of the manuscript. The manuscript will undergo copyediting, typesetting, and review of the resulting proof before it is published in its final form. Please note that during the production process errors may be discovered which could affect the content, and all legal disclaimers that apply to the journal pertain. 


\section{Highlights}

- $\mathrm{MgB}_{2}$ wires doped with Ir (iridium) were prepared and reacted in $\mathrm{Ar}$.

- The solubility limit of $\mathrm{Ir}$ in the $\mathrm{MgB}_{2}$ lattice is not larger than 1.5 at.\% relative to $\mathrm{Mg}$.

- The critical current density is degraded in the Ir-doped samples.

- The main flux pinning mechanism was identified as $\Delta \mathrm{T}_{\mathrm{c}}$ pinning. 


\title{
Influence of iridium doping in $\mathrm{MgB}_{2}$ superconducting wires
}

\author{
J.-C. Grivel* \\ Department of Energy Conversion and Storage, Technical University of Denmark, DK-4000 \\ Roskilde, Denmark
}

\section{Abstract}

$\mathrm{MgB}_{2}$ wires with iridium doping were manufactured using the in-situ technique in a composite $\mathrm{Cu}-\mathrm{Nb}$ sheath. Reaction was performed at $700^{\circ} \mathrm{C}, 800^{\circ} \mathrm{C}$ or $900^{\circ} \mathrm{C}$ for $1 \mathrm{~h}$ in argon atmosphere. A maximum of about 1.5 at.\% Ir replaces $\mathrm{Mg}$ in $\mathrm{MgB}_{2}$. The superconducting transition temperature is slightly lowered by Ir doping. The formation of $\mathrm{IrMg}_{3}$ and $\mathrm{IrMg}_{4}$ secondary phase particles is evidenced, especially for a nominal stoichiometry with 2.0 at.\% Ir doping. The critical current density and accommodation field of the wires are strongly dependent on the Ir content and are generally weakened in the presence of $\mathrm{Ir}$, although the effect is less pronounced at lower temperatures.

Keywords: $\mathrm{MgB}_{2}$; doping; iridium; wires

\section{*Corresponding author}

Email: jean@dtu.dk 


\section{Introduction}

Owing to its critical temperature $\left(\mathrm{T}_{\mathrm{c}}\right)$ of $39 \mathrm{~K}$. which is intermediate between those of classical low temperature superconductors and high- $\mathrm{T}_{\mathrm{c}}$ cuprates, associated to advantages such as low materials costs, absence of weak links at grain boundaries [1] and straightforward processing as metal-sheathed wires [2], $\mathrm{MgB}_{2}$ is an outstanding material in view of small and large scale power applications. During recent years, various prototypes have been developed, including cryogenfree MRI systems [3,4] and induction heating units [5], while other applications including generators, transformers, fault current limiters as well as magnetic shields for deep-space missions are foreseen for a near future [6,7]. Furthermore, based on the low activation of $\mathrm{MgB}_{2}$ upon neutron irradiation [8], $\mathrm{MgB}_{2}$ wires are serious contenders for use in future commercial fusion reactors. Nevertheless, for this latter usage as well as some specific applications involving high magnetic fields, improvements are still needed to enhance the critical current density $\left(\mathrm{j}_{\mathrm{c}}\right)$ performance of $\mathrm{MgB}_{2}$ wires. In this endeavour, different strategies can be adopted like grain size refinement $[9,10]$, nanoparticle inclusions [11-13] or doping with other elements. Introducing carbon on the boron sites was shown to be very efficient under high magnetic fields [14-17], but tends to decrease the self-field $\mathrm{j}_{\mathrm{c}}$ so that further improvements are still needed if performance has to be improved in a wide magnetic field range. Beside boron site doping, numerous attempts have been made at doping various elements on the Mg sites. Unfortunately, while $\mathrm{Al}$ can replace up to 40 at.\% $\mathrm{Mg}$ [18-21], for other elements solubility is limited to a few percent in most cases [22-40] and is often below detection limit [41-46].

Platinum group metals present various behaviours. $\mathrm{Pd}$ and $\mathrm{Pt}$ are virtually not soluble in $\mathrm{MgB}_{2}$ [41], whereas about 1 at.\% Ru and Os can be substituted for $\mathrm{Mg}[34,35]$. Rh has a slightly higher solubility limit of $2.2-2.5$ at.\% [40]. Iridium appears to be an exception with a maximum 
solubility limit of 6 at.\% relative to $\mathrm{Mg}$ according to a study performed on bulk samples [36]. In that work, the effect of Ir substitution on the critical current density $\left(\mathrm{j}_{\mathrm{c}}\right)$ was not reported. Furthermore, the determination of 6 at. $\%$ as a solubility limit was not straightforward, because $T_{c}$ as well as the lattice parameters given in [36] were continuously varying up to 12 at.\%, whereas impurity peaks were already visible in the XRD patterns for 2 at.\% Ir doping. It was thus of interest to reassess the solubility limit of $\mathrm{Ir}$ in $\mathrm{MgB}_{2}$ and to study its possible effect on $\mathrm{j}_{\mathrm{c}}$. In principle, substitutions on the $\mathrm{Mg}$ sites are not expected to result in ic improvements due to enhanced interband scattering [47,48]. However, other effects such as the appearance of nanometer sized non-superconducting particles beyond the solubility limit of dopants or inhomogeneities in the dopant concentration might positively affect the behavior of $\mathrm{MgB}_{2}$ under applied magnetic fields so that potential substitutions on $\mathrm{Mg}$ sites are still worth studying.

\section{Experimental details}

The starting reagents were elemental powders: $\mathrm{Mg}$ (Alfa Aesar, $99.8 \%$ purity), amorphous boron (Aldrich, 95-97\%) and Ir (Alfa Aesar, $99.8 \%$ ). They were mixed according to the following nominal ratios: $\mathrm{Mg}_{1-\mathrm{x}} \operatorname{Ir}_{x} \mathrm{~B}_{2.04}(0.00 \leq \mathrm{x} \leq 0.02$ with $\Delta \mathrm{x}=0.01)$. The slightly B-enriched starting stoichiometry is based on a earlier work taking into consideration the impurities (including some $\mathrm{Mg}$ ) present in the B commercial powder used for the present work [49]. Mixing was performed in a mechanical blender (Bachofen, type T2C). The mixed powders were then loaded into $4 \mathrm{~cm}$ long $\mathrm{Nb}$ tube sections with $5 \mathrm{~mm}$ external diameter and $0.3 \mathrm{~mm}$ wall thickness (Goodfellow Ltd). These tubes were mechanically deformed by groove rolling into wires with $4.0 \mathrm{~mm}$ external diameter and inserted into $\mathrm{Cu}$ tubes (Goodfellow Ltd., $5 \mathrm{~mm}$ external diameter, $0.5 \mathrm{~mm}$ wall thickness). The composite tubes and the powder core were further deformed into wires with square cross section of about $1.6 \times 1.6 \mathrm{~mm}^{2} .6 \mathrm{~cm}$ long pieces of the wires were heat 
treated at different temperatures $\left(700^{\circ} \mathrm{C}, 800^{\circ} \mathrm{C}\right.$ or $\left.900^{\circ} \mathrm{C}\right)$ for $1 \mathrm{~h}$ under $\mathrm{Ar}$ atmosphere with a heating rate of $100^{\circ} \mathrm{C} / \mathrm{h}$ and furnace cooling.

XRD patterns were recorded in a Bruker X-ray diffractometer with $\mathrm{CuK} \alpha$ radiation $(\lambda=1.5406$ $\AA$ ) on powders that had been mechanically extracted from the wires after heat treatment. Silicon powder (Alfa Aesar, 99.999\%) was mixed to the ground powders as an internal standard for lattice parameters determination. The calculations were performed with the UnitCell least square refinement programme [50]. The microstructure of the ceramic core of the wires and the composition of the impurity phases present after reaction at $700^{\circ} \mathrm{C}, 800^{\circ} \mathrm{C}$ or $900^{\circ} \mathrm{C}$ were studied by means of scanning electron microscopy (SEM) in a table-top TM3000 microscope from HITACHI equipped with a QUANTAX 70 EDS analyser. For magnetic measurements, $8.0 \pm 0.5$ $\mathrm{mm}$ long segments were cut in the middle of the reacted wires. The superconducting critical temperature $\left(\mathrm{T}_{\mathrm{c}}\right)$ was determined as the onset of the diamagnetic transition measured by means of a vibrating sample magnetometer (VSM) in a CRYOGENIC Ltd Mini-CFMS under a magnetic field of $1 \mathrm{mT}$ applied parallel to the $\mathrm{MgB}_{2}$ filament after cooling under zero field conditions. For the estimation of the critical current density, magnetisation hysteresis loops were recorded with the magnetic field parallel to the long axis of the wires and $j_{c}$ was calculated using the Bean model. The accommodation field $\left(B^{*}\right)$ was determined as the magnetic field at which $\mathrm{j}_{\mathrm{c}}$ is reduced to $90 \%$ of its value under self-field conditions.

\section{Results and discussion}

Figure 1 shows the XRD patterns of the powders mechanically extracted from the wires reacted during $1 \mathrm{~h}$ at different temperatures. While $\mathrm{MgB}_{2}$ is the dominant phase in all cases, there are some important differences to note. Unreacted $\mathrm{Mg}$ is still present in the undoped sample reacted at $700^{\circ} \mathrm{C}$, showing that these conditions are not good enough for ensuring the completion of the 
$\mathrm{MgB}_{2}$ phase formation. In contrast, no $\mathrm{Mg}$ was detected in the other samples. The pattern of the ceramic core of the undoped wire also reveals other low intensity peaks at $2 \theta=35.3^{\circ}, 37.3^{\circ}$, $39.6^{\circ}$ and $44.4^{\circ}$, which could be due to some $\mathrm{Mg}_{2} \mathrm{Cu}$ that might form if liquid $\mathrm{Mg}$ infiltrates through the $\mathrm{Nb}$ protective layer and reacts with the outer $\mathrm{Cu}$ sheath. It should however be noted that $\mathrm{Mg}_{2} \mathrm{Cu}$ is not stable above $568^{\circ} \mathrm{C}$ [51] so that it can be excluded that this impurity is formed during the reaction at $700^{\circ} \mathrm{C}$. Furthermore, no $\mathrm{Cu}$ was detected in the core of this wire by EDS analysis. These peaks can in fact also be due to unreacted boron. Indeed, the commercial boron powder used for this study, although labelled as "amorphous", presents broad XRD reflections at $2 \theta$ angles corresponding to the values listed above. This conclusion is more compatible with the observation of unreacted $\mathrm{Mg}$. A reflection at $2 \theta \approx 40.8^{\circ}$ in the sample with 2 at. $\%$ Ir substitution for $\mathrm{Mg}$, reacted at $700^{\circ} \mathrm{C}$, could be due to elemental Ir.

The lattice parameters are listed in Table 1 . There is no obvious trend for a systematic influence of the Ir content on the a-axis or c-axis length. This is very different from the result in [36], according to which at 2 at.\% Ir substitution for $\mathrm{Mg}$, the a-axis length was reported to increase by $0.0008 \AA$ and the c-axis length to decrease by as much as $0.08 \AA$. Nevertheless, the XRD patterns of the present samples contain much less impurity peaks than in [36] for the same Ir doping level.

Fig.2 presents overview SEM micrographs in backscattering mode of all samples after reaction. For all 3 reaction temperatures, the undoped samples exhibit a typical microstructure for $\mathrm{MgB}_{2}$ ceramic samples with significant porosity (black areas) and boron-rich $\mathrm{Mg}$-B phases (dark grey) embedded in the $\mathrm{MgB}_{2}$ matrix (light grey). The only, albeit significant difference in the Ir- doped samples is the appearance of white particles that increase in number for higher doping level. Compositional analysis of these particles was performed by means of EDS. A 
typical result is shown in Fig. 3 for the sample with 2 at.\% Ir doping reacted at $800^{\circ} \mathrm{C}$. As expected from their bright contrast, the white particles are rich in Ir. They also contain Mg but no quantifiable amount of B. Their composition corresponds to $\operatorname{IrMg}_{3}$ and $\operatorname{IrMg}_{4}$, two phases which happen to be stable up to $1020^{\circ} \mathrm{C}$ and $920^{\circ} \mathrm{C}$ respectively according to Nayeb-Hashemi and Clark [52]. The dark grey particles were confirmed to consist of B-rich magnesium borides with preponderance of $\mathrm{MgB}_{7}$, whereas $\mathrm{MgB}_{4}$ and $\mathrm{MgB}_{12}$ are less frequent. Another type of defect is emphasized in Fig.3a by a circle. In this area, only $\mathrm{Mg}$ was detected in association with oxygen. This is therefore a cluster of $\mathrm{MgO}$, a phase which is also evidenced in the XRD patterns by a peak at $2 \theta \approx 62.2^{\circ}$ (Fig.1), especially for reaction temperatures above $700^{\circ} \mathrm{C}$. EDS elemental analysis performed on large areas $\left(\approx 10.000 \mu \mathrm{m}^{2}\right)$ yield $\mathrm{Mg}: \mathrm{Ir}$ atomic ratios very close to the nominal stoichiometry for all samples with 1 at.\% and 2 at.\% Ir substitution, notwithstanding of the heat treatment temperature. On the other hand, local EDS analysis on areas that do not include white particles in Fig. 3a reveal an Ir at.\% ratio of $1.58 \pm 0.24$ relative to $\mathrm{Mg}$. This value is lower than the overall Ir 2.0 at.\% nominal substitution level. Since it cannot be excluded that these analyzed areas include some smaller $\mathrm{IrMg}_{3}$ or $\mathrm{IrMg}_{4}$ particles that cannot be distinguished from the $\mathrm{MgB}_{2}$ matrix or that are lying just below the cross-section surface, it must be considered that $x=0.0158 \pm 0.0024$ is an upper limit for the solubility of $\operatorname{Ir}$ in $\operatorname{Mg}_{1-\mathrm{x}} \mathrm{Ir}_{\mathrm{x}} \mathrm{B}_{2}$. From these observations, it can be concluded that the actual substitution level of Ir in $\mathrm{MgB}_{2}$ is rather low under the present experimental conditions and comparable to that of Ru or Os $[34,35]$. This is further supported by the superconducting critical temperature $\left(T_{c}\right)$ that is only slightly affected by the presence of Ir (Fig. 4 and Table 1). Except for the samples reacted at $700^{\circ} \mathrm{C}$, there is a tendency for a lowering of $T_{c}$ with increase of the Ir content, but it is much smaller than reported in [36] based on electrical resistivity measurements that were showing a $\mathrm{T}_{\mathrm{c}}$ of $33.2 \mathrm{~K}$ for 2 at.\% 
Ir doping. The inset in Fig.4 shows typical data for the three doping levels (reaction at $800^{\circ} \mathrm{C}$ ). The transition width is not dependent on the amount of Ir. Slight irregular features close to the onset of the diamagnetic transition in the samples with $X=0.00$ and 0.02 could suggest that there are two distinct transitions that may originate from a phase separation. However, they are more likely attributable to the accuracy of the temperature control (measurement accuracy of about $0.05 \mathrm{~K}$ for these data collected with a heating rate of $2 \mathrm{~K} / \mathrm{min}$ ) as well as dynamic effects in the magnetic flux penetration into the samples. Since $\mathrm{IrMg}_{3} / \mathrm{IrMg}_{4}$ particles are already seen in the SEM images for 1 at.\% Ir doping, the slight $\mathrm{T}_{\mathrm{c}}$ decrease observed in the present samples could in fact be due to stoichiometry effects resulting from $\mathrm{Mg}$ depletion [53-57] rather than from actual Ir doping, although the near saturation of the $T_{c}$ decrease when going from $x=0.01$ to $\mathrm{x}=0.02$ in the samples reacted at $700^{\circ} \mathrm{C}$ and $800^{\circ} \mathrm{C}$ fits well with a solubility limit situated in between these two values. Furthermore, the fact that stoichiometry variations affect the $T_{c}$ of the $\mathrm{MgB}_{2}$ phase is not supported by studies on single crystals [58], so that the presently observed effect is most probably due to $\mathrm{Ir}$ substitution in the $\mathrm{MgB}_{2}$ lattice.

The critical current density of the wires was calculated from $\mathrm{M}(\mathrm{H})$ hysteresis loops using the Bean model with the following formula corresponding to elongated samples with the longest dimension parallel to the applied magnetic field:

$$
j_{c}=\frac{2 \Delta M}{a\left(1-\frac{a}{3 b}\right) V}
$$

where $\Delta \mathrm{M}$ is the opening of the volume magnetisation hysteresis loop, $\mathrm{a}$ and $\mathrm{b}$ are the linear dimensions of the cross-section of the superconducting core of the wire perpendicular to the applied magnetic field $(\mathrm{a}<\mathrm{b})$, and $\mathrm{V}$ the volume of the superconducting core. 
Fig.5 shows two sets of examples of $\mathrm{M}(\mathrm{H})$ loops at $10 \mathrm{~K}, 20 \mathrm{~K}$ and $30 \mathrm{~K}$ for the samples without Ir and the highest studied Ir content after reaction at $800^{\circ} \mathrm{C}$ for $1 \mathrm{~h}$. Besides lower magnetization values at equivalent temperatures, it can be observed that the asymmetry for the undoped sample is more pronounced, indicating weaker flux pinning in the Ir doped wire. This last feature is reflected in the stronger field dependence of the normalized $\mathrm{j}_{\mathrm{c}}$ versus field curves for the Ir doped wire, also shown in Fig.5. This behavior has been systematically observed for all Ir-doped samples and is reflected in the $\mathrm{B}^{*}$ values (= the applied field resulting in a reduction of $\mathrm{j}_{\mathrm{c}}$ to $90 \%$ of its value in self field), which are listed in Table 1 . At $30 \mathrm{~K}$, $\mathrm{B} *$ is systematically highest in the undoped wires for all reaction temperatures. Nevertheless, with decreasing temperature, the $\mathrm{B}^{*}$ values increase faster in the doped wires so that at $10 \mathrm{~K}$, the $\mathrm{B}^{*}$ of the 1 at.\% doped wires is comparable to that of the undoped wire notwithstanding of reaction temperature.

Fig.6a and $\mathrm{b}$ compares the $\mathrm{j}_{\mathrm{c}}$ versus applied magnefic field (B) of all samples at $10 \mathrm{~K}$ and $30 \mathrm{~K}$. In these graphs, only the $j_{c}$ values at a few fields are plotted for the sake of clarity. Except for the $\mathrm{x}=0.01$ sample reacted at $900^{\circ} \mathrm{C}$, there is a clear tendency for lower $\mathrm{j}_{\mathrm{c}}$ values for increasing $\mathrm{Ir}$ contents in the wires. However, at $10 \mathrm{~K}$, the performance of the $\mathrm{x}=0.01$ wires reacted at $700^{\circ} \mathrm{C}$ and $800^{\circ} \mathrm{C}$ become closer to that of the undoped wires, especially at $\mathrm{B} \geq 2 \mathrm{~T}$. The lower $\mathrm{j}_{\mathrm{c}}$ of the wire with $\mathrm{x}=0.01$, reacted at $900^{\circ} \mathrm{C}$ might be due to macroscopic defects such as local failure of the $\mathrm{Nb}$ protective layer separating the $\mathrm{MgB}_{2}$ core from the outer $\mathrm{Cu}$ sheath. The general trend for lower $\mathrm{j}_{\mathrm{c}}$ values in the doped wires may not be exclusively due to the substitution of Ir in the $\mathrm{MgB}_{2}$ phase. In fact, the amount of impurities in the form of $\mathrm{IrMg}_{3}$ and $\mathrm{IrMg}_{4}$ is relatively large, especially in the samples with $\mathrm{x}=0.02$. Their volume has not been taken into account in the calculation of $j_{c}$. 
The normalized pinning force $\left(\mathrm{F}_{\mathrm{p}} / \mathrm{F}_{\mathrm{p} \text { max }}\right)$ is plotted versus $\left(\mathrm{B} / \mathrm{B}_{\mathrm{Fp} \text { max }}\right)$ in Fig.7 for all samples and compared to the three different models corresponding to surface pinning (2), normal point pinning (3) and $\Delta \kappa$ pinning (4) [59]:

$$
\begin{aligned}
& f(b)=\frac{25}{16} \sqrt{b}\left(1-\frac{b}{5}\right)^{2} \\
& f(b)=\frac{9}{4} b\left(1-\frac{b}{3}\right)^{2} \\
& f(b)=3 b^{2}\left(1-\frac{2 b}{3}\right)
\end{aligned}
$$

where $f(b)$ is the pinning force $\mathrm{F}_{\mathrm{p}}$ divided by the maximum value of $\mathrm{F}_{\mathrm{p}}\left(=\mathrm{F}_{\mathrm{pmax}}\right)$ and $b=\mathrm{B} / \mathrm{B}_{\mathrm{Fpmax}}$ is the applied magnetic field $\mathrm{B}$ divided by the field corresponding to $\mathrm{F}_{\mathrm{pmax}}$.

At $10 \mathrm{~K}$, the data for all samples show a similar dependence below the pinning force maximum, with a shape close to that predicted for $\Delta T_{c}$ pinning. At higher fields, the samples with 1 at.\% Ir doping or without Ir continue following the same model, whereas the 2 at.\% samples all depart from this trend and their behavior becomes closer to the surface pinning model. As the temperature is increased, the behavior of the undoped and 1 at.\% Ir doped wires is unchanged, but that of the 2 at.\% Ir doped wire is moving more towards surface pinning, also at low applied magnetic fields.

Of course, the fact that the normalized pinning force follows a particular pinning model does not necessarily mean that this kind of pinning is the only one at play, but generally reflects the dominant pinning mechanism. Surface pinning is playing an important role in $\mathrm{MgB}_{2}$ polycrystalline samples [60] and is most probably also acting in the samples produced within the present study. However, here $\Delta \mathrm{T}_{\mathrm{c}}$ pinning is obviously rather important in most samples, which may be due to inhomogeneities, themselves resulting from the fact that the reacted powder inside 
the wires cannot be extracted, homogenized by mechanical means and reacted again. Interestingly, Ir doping tends to shift the $\mathrm{F}_{\mathrm{p}} / \mathrm{F}_{\mathrm{p} \text { max }}$ curves towards the surface pinning behavior. This could be due to either weakening of the $\Delta T_{c}$ pinning or a relative increase of surface pinning. The latter effect could result from a decrease of the $\mathrm{MgB}_{2}$ grain size but no evidence was found for XRD peak broadening. On the other hand, the Mg-rich side of the Ir-Mg binary phase diagram [52] shows that interaction with Ir induces a lowering of the melting point of $\mathrm{Mg}$, with formation of a molten phase at $615^{\circ} \mathrm{C}$ (eutectic). This means that adding Ir can increase the amount of liquid during reaction, which can potentially help homogenizing the $\mathrm{MgB}_{2}$ phase and thus decrease the $\Delta \mathrm{T}_{\mathrm{c}}$ pinning contribution. The admixture of various elements such as $\mathrm{Ag}, \mathrm{Cu}$, $\mathrm{Bi}, \mathrm{Sb}, \mathrm{Ge}, \mathrm{Sn}$ and In that also result in a decrease of the $\mathrm{Mg}$ melting temperature, has been the topic of a few previous publications [8,61-66]. Unfortunately, the effect of these additives on the flux pinning mechanism behavior does not appear to have been documented except in the case of In, where a similar tendency was observed, although in that case the samples consisted in bulk pellets [46]. Systematic studies would be useful to find out whether elements inducing a lowering of liquid phase formation should be avoided, or the use of such elements requires developing specific heat treatments for minimizing the weakening of $\Delta \mathrm{T}_{\mathrm{c}}$ pinning.

\section{Conclusion}

Under the present experimental conditions, i.e. in-situ reaction at $700^{\circ} \mathrm{C}, 800^{\circ} \mathrm{C}$ or $900^{\circ} \mathrm{C}$ for 1 $\mathrm{h}$ inside $\mathrm{Cu} / \mathrm{Nb}$-sheathed wires the amount of Ir that can be substituted for $\mathrm{Mg}$ in $\mathrm{MgB}_{2}$ is limited to 1.6 at. \% at most. Impurity phases consisting of $\operatorname{IrMg}_{3}$ and $\mathrm{IrMg}_{4}$ with diameters reaching up to $4 \mu \mathrm{m}$ form in the $\mathrm{MgB}_{2}$ matrix. $\mathrm{T}_{\mathrm{c}}$ is slightly lowered by Ir substitution. On the other hand, the critical current density is decreased and the flux pinning strength is weaker in the doped samples. A progressive shift from $\Delta \mathrm{T}_{\mathrm{c}}$ pinning to surface pinning mechanism was observed in Ir-doped 
samples, especially at $30 \mathrm{~K}$. The solubility limit of Ir is lower than previously reported and is similar to that of other platinum group metals ( $\mathrm{Ru}, \mathrm{Rh}$ and $\mathrm{Os})$, with comparable effects on $\mathrm{T}_{\mathrm{c}}$.

\section{Acknowledgments}

Mr. Henrik Paulsen is gratefully acknowledged for preparing the polished cross-sections of the samples for SEM investigations. 


\section{References}

[1] D.C. Larbalestier, L.D. Cooley, M.O. Rikel, A.A. Polyanskii, J. Jiang, S. Patnaik, X.Y. Cai, D.M. Feldmann, A. Gurevich, A.A. Squitieri, M.T. Naus, C.B. Eom, E.E. Hellstrom, R.J. Cava, K.A. Regan, N. Rogado, M.A. Hayward, T. He, J.S. Slusky, P. Khalifah, K. Inumaru and M. Haas, Strongly linked current flow in polycrystalline forms of the superconductor $\mathrm{MgB}_{2}$, Nature $410(2001) 186-189$

[2] V. Braccini, D. Nardelli, R. Penco and G. Grasso, Development of ex-situ processed $\mathrm{MgB}_{2}$ wires and their applications to magnets, Physica C 456 (2007) 209 - 217

[3] M.Razeti, S. Angius, L. Bertora, D. Damiani, R. Marabotto, M. Modica, D. Nardelli, M. Perrella and M. Tassisto, Construction and operation of cryogen free $\mathrm{MgB}_{2}$ magnets for open MRI systems, IEEE Trans. Appl. Supercond. 18 (2008) 882-886

[4] S. Hahn, J. Bascunan, H. Lee, E.S. Bobrov, W.Kim, M.C. Ahn and Y. Iwasa, Operation and performance analyses of 350 and $700 \mathrm{MHz}$ low-/high-temperature superconductor nuclear magnetic resonance magnets: A march toward operating frequencies above 1GHz, J. Appl. Phys. 105 (2009) 024501

[5] M. Runde, A. Stenvall, N. Magnusson, G. Grasso and R. Mikkonen, $\mathrm{MgB}_{2}$ coils for a DC superconducting induction heater, J. Phys. Conf. Ser. 97 (2008) 012159

[6] M. Putti and G. Grasso, $\mathrm{MgB}_{2}$, a two-gap superconductor for practical applications, MRS Bulletin 36 (2011) 608-613

[7] R. Battiston, W.J. Burger, V. Calvelli, V.I. Datskov, S. Farinon and R. Musenich, Superconducting magnets for astroparticle shielding in interplanetary manned missions, IEEE Trans. Appl. Supercond. 23 (2013) 4101604 
[8] Y.Hishinuma, A.Kikuchi, K. Matsuda, K. Nishimura, Y.Kubota, S.Hata, S. Yamada and T. Takeuchi, Microstructure and superconducting properties of $\mathrm{Cu}$ addition $\mathrm{MgB}_{2}$ multifilamentary wires using boron isotope powder as the boron source material, Physics Procedia 36 (2012) $1486-1491$

[9] A. Gümbel, J. Eckert, G. Fuchs, K. Nenkov, K.-H. Müller and L. Schultz, Improved superconducting properties in nanocrystalline Bulk $\mathrm{MgB}_{2}$, Appl. Phys. Lett. 80 (2002) 2725 2727

[10] Y. Katsura, A. Yamamoto, S. Ueda, I. Iwayama, S. Horii, J.-I. Shimoyama and K. Kishio, Flux pinning properties of undoped and $\mathrm{C}$-doped $\mathrm{MgB}_{2}$ bulks with controlled grain sizes, Physica C 460 - 462 (2007) 572 - 573

[11] J. Wang, Y. Bugoslavsky, A. Berenov, L. Cowey, A.D. Caplin, L.F. Cohen, L.D. Cooley, X. Song and D.C. Larbalestier, High critical current density and improved irreversibility field in bulk $\mathrm{MgB}_{2}$ made by a scalable, nanoparticle addition route, Appl. Phys. Lett. 81 (2002) 2026 2028

[12] E. Babic, N. Novosel, D. Pajic, S. Galic, K. Zadro and D. Drobac, Magnetic nanoparticles in $\mathrm{MgB}_{2}$ : vortex pinning, pair breaking and connectivity, J. Magn. Magn. Mater. 400 (2016) 88 92

[13] N. Novosel, S. Galic, D. Pajic, K. Zadro and E. Babic, Enhancing superconducting properties of $\mathrm{MgB}_{2}$ by addition of magnetic particles, J. Supercond. Nov. Magn. 28 (2015) 425 430

[14] T. Takenobu, T. Ito, D.H. Chi, K.Prassides and Y.Iwasa, Intralayer carbon substitution in the $\mathrm{MgB}_{2}$ superconductor, Phys. Rev. B 64 (2001) 134513 (3pp) 
[15] S. Lee, T.Masui, A. Yamamoto, H. Uchiyama and S. Tajima, Crystal growth of C-doped $\mathrm{MgB}_{2}$ superconductors: accidental doping and inhomogeneity, Physica C 412-414 (2004) 31-35

[16] A.Bharathi, S. Jemima Balaselvi, S. Kalavathi, G.L.N Reddy, V.Sankara Sastry, Y. Hariharan and T.S Radhakrishnan, Carbon solubility and superconductivity in $\mathrm{MgB}_{2}$, Physica $\mathrm{C}$ 370 (2002) 211-218

[17] X.P Zhang, D.L. Wang, Z.S. Gao, L.Wang, Y.W. Ma, Z.P. Qi and K. Watanabe, The doping effect of activated carbon on the superconducting properties of $\mathrm{MgB}_{2}$ tapes, Supercond. Sci. Technol 21 (2008) 075008 (5pp)

[18] J.S. Slusky, N. Rogado, K.A Regan, M.A Hayward, P.Khalifah, T.He, K. Inumaru, S.M Loureiro, M.K. Haas, H.W Zandbergen and R.J Cavá, Loss of superconductivity with the addition of $\mathrm{Al}$ to $\mathrm{MgB}_{2}$ and a structural transition in $\mathrm{Mg}_{1-\mathrm{x}} \mathrm{Al}_{\mathrm{X}} \mathrm{B}_{2}$, Nature 410 (2001) 343-354.

[19] J.Y. Xiang, D.N. Zheng, J.Q. Li, S.L Li, H.H Wen and Z.X.Zhao, Effects of Al doping on the superconducting and structural properties of $\mathrm{MgB}_{2}$, Physica C 386 (2003) 611-615

[20] G.J. Xu, J.-C. Grivel, A.B Abrahamsen, X.P. Chen and N.H. Andersen, Structure and superconductivity of double-doped $\mathrm{Mg}_{1-\mathrm{x}}\left(\mathrm{Al}_{0.5} \mathrm{Li}_{0.5}\right)_{\mathrm{x}} \mathrm{B}_{2}$, Physica C 399 (2003) 8-14

[21] G.J. Xu, J.-C. Grivel, A.B Abrahamsen, X.P. Chen and N.H. Andersen, Superconducting properties of $\mathrm{Zn}$ and $\mathrm{Al}$ double-doped $\mathrm{Mg}_{1-\mathrm{x}}\left(\mathrm{Zn}_{0.5} \mathrm{Al}_{0.5}\right)_{\mathrm{x}} \mathrm{B}_{2}$, Physica C 403(2004) 113-118

[22] D. Goto, T. Machí, Y. Zhao, N. Koshizuka, M. Murakami and S. Arai, Improvement of critical current density in $\mathrm{MgB}_{2}$ by $\mathrm{Ti}, \mathrm{Zr}$ and Hf doping, Physica C 392-396 (2003) 272 -275 [23] N. Hörhager, M. Eisterer, H.W. Weber, T. Prikhna, T. Tajima and V.F Nesterenko, Ti and Zr doped $\mathrm{MgB}_{2}$ bulk superconductors, J. Phys.:Conf. Ser. 43 (2006) 500-504

[24] Y. Takikawa, M. Takeda, M.Migita, M.Uehara, T.Kuramoto and Y. Kimishima, Effect of W-addition on pinning property of $\mathrm{MgB}_{2}$, Physica C 471 (2011) 905-907 
[25] C.H Cheng, Y. Yang, C.Ke and H.T. Lin, Iron doping effect on superconducting properties of $\mathrm{MgB}_{2}$, Physica C 470 (2010) 1092-1095

[26] S.M. Kazakov, M. Angst, J. Karpinski, I.M. Fita and R. Puzniak, Substitution effect of Zn and $\mathrm{Cu}$ in $\mathrm{MgB}_{2}$ on $\mathrm{T}_{\mathrm{c}}$ and structure, Solid State Commun. 119 (2001) 1-5

[27] E. Martinez, L.A. Angurel, R. Navarro, A. Millán, C. Rillo and M. Artigas, Study of MgB 2 powders and $\mathrm{Cu} / \mathrm{MgB}_{2}$ powder-in-tube composite wires with $\mathrm{Zn}$ addition, IEEE Trans. Appl. Supercond. 13 (2003) 3210-3213

[28] U.P. Trociewitz, P.V.P.S.S. Sastry, A. Wyda, K. Crockett and J./ Schwartz, Magnetic properties of neutron irradiated and doped $\mathrm{MgB}_{2}$ superconductors, IEEE Trans. Appl. Supercond. 13 (2003) 3320-3323

[29] H. Zhang, J. Zhao and L. Shi, The charge transfer induced by Cr doping in $\mathrm{MgB}_{2}$, Physica C $424(2005) 79-84$

[30] N. Suemitsu, T. Masui, S. Lee and S. Tajima, Mn substitution effect on superconducting properties of $\mathrm{MgB}_{2}$ single crystals, Physica C 445-448 (2006) 39-41

[31] S. Agrestini, C. Metallo, M. Filippi, L. Simonelli, G. Campi, C. Sanipoli, E. Liarokapis, S. De Negri, M. Giovanni, A. Saccone, A. Latini and A. Bianconi, Substitution of Sc for Mg in $\mathrm{MgB}_{2}$ : Effects on transition temperature an Kohn anomaly, Phys. Rev. B 70 (2004) 134514 (5pp).

[32] K.M. Elsabawy, Narrow range of hafnium doping for promoted mechanical properties and critical current density $\left(\mathrm{J}_{\mathrm{c}}\right)$ values of $\mathrm{Mg}_{1-\mathrm{x}} \mathrm{Hf}_{\mathrm{x}} \mathrm{B}_{2}$ superconductor, J.Supercond.Nov. Magn. 24 (2011) 1853-1861

[33] X.L. Xu, J.D. Guo, Y.Z. Wang and X. Wang, Au-doping effects in the $\operatorname{Mg}_{1-x} A_{u_{x}} B_{2}$ series, Mater. Letters 58 (2003) 142-145. 
[34] J.-C. Grivel, S. Namazkar, A. Alexiou and O.J. Holte, Preparation and characterization of Os doped $\mathrm{MgB}_{2}$, Physica C 507 (2014) 70-74

[35] J.-C. Grivel, O.J. Holte, Preparation and characterisation of Ru doped $\mathrm{MgB}_{2}$, Physica C 495 (2013) 229-232.

[36] M.M.A. Sekkina and K.M. Elsabawy, Narrow range of iridium-substitution on $\mathrm{Mg}_{1-\mathrm{x}} \mathrm{Ir}_{\mathrm{x}} \mathrm{B}_{2}$ superconductor, Physica C 391 (2003) 217-222

[37] L. Shi, S. Zhang and H. Zhang, Effects of Co and Mn doping on the structure and superconductivity of $\mathrm{MgB}_{2}$, Solid State Commun. 147 (2008) 27-30

[38] K. Rogacki, B. Batlogg, J. Karpinski, N.D. Zhigadlo, G. Schuck, S.M. Kazakov, P. Wägli, R. Puźniak, A. Wiśniewski, F. Carbone, A. Brinkman and D. van der Marel, Strong magnetic pair breaking in Mn-substituted $\mathrm{MgB}_{2}$ single crystals, Phys. Rev. B 73 (2006) 174520 (8pp)

[39] J. Karpinski, N.D. Zhigadlo, S. Katrych, K. Rogacki, B. Batlogg, M. Tortello and R. Puzniak, $\mathrm{MgB}_{2}$ single crystals substituted with Li and with Li-C: Structural and superconducting properties, Phys. Rev. B 77 (2008) 214507

[40] A. Pitillas and J.-C. Grivel, Preparation and characterisation of $\mathrm{Mg}_{1-\mathrm{x}} \mathrm{Rh}_{\mathrm{x}} \mathrm{B}_{2}$, J. Supercond. Nov. Magn. 28 (2015) 2495 - 2500

[41] J.-C. Grivel, A. Pitillas, S. Namazkar, A. Alexiou and O.J. Holte, Preparation and characterization of $\mathrm{MgB}_{2}$ with Pd, Pt and Re doping, Physica C 520 (2016) 37 - 41 [42] M.A. Aksan, M.E. Yacini and A. Güldeste, Co-addition into $\mathrm{MgB}_{2}$ : The structural and electronic properties of $\left(\mathrm{MgB}_{2}\right)_{2-\mathrm{x}} \mathrm{Co}_{\mathrm{x}}$, J. Alloys and Compounds 424 (2006) 33-40 
[43] C.H Cheng, Y. Zhao, X.T Zhu, J.Nowotny, C.C Sorrell, T. Finlayson and H. Zhang, Chemical doping effect on the crystal structure and superconductivity of $\mathrm{MgB}_{2}$, Physica $\mathrm{C} 386$ (2003) 588-592.

[44] J. Karpinski, N.D. Zhigadlo, S. Katrych, R. Puzniak, K. Rogacki and R. Gonnelli, Single crystals of MgB2: Synthesis, substitutions and properties, Physica C 456 (2007) 3 - 13

[45] J.-C. Grivel and M. Burdusel, Preparation and characterization of Sc doped $\mathrm{MgB}_{2}$ wires, Physica C 528 (2016) $65-72$

[46] J.-C. Grivel, Attempts at doping indium in $\mathrm{MgB}_{2}$, Physica C 531 (2016) 67 - 71

[47] M. Iavarone, R. di Capua, A.E. Koshelev, W.K. Kwok, F. Chiarella, R. Vaglio, W.N. Kang, E.M. Choi, H.J. Kim, S.I. Lee, A.V. Pogrebnyakov, J.M. Redwing and X.X. Xi, Effect of disorder in $\mathrm{MgB}_{2}$ thin films, Phys. Rev. B 71 (2005) 214502

[48] B. Kang, M.-S. Park, H.-S. Lee, M.-H. Jung and S.-I. Lee, Comparison between Al and C substitutions in the upper critical field of $\mathrm{MgB}_{2}$ single crystals, J. Korean Phys. Soc. 58 (2011) $498-502$

[49] J.C. Grivel, A. Alexiou, K. Rubešová, X. Tang, N.H. Andersen, M. von Zimmermann and A. Watenphul, Preparation and characterization of $\mathrm{Mg}_{1-\mathrm{x}} \mathrm{B}_{2}$ bulk samples and $\mathrm{Cu} / \mathrm{Nb}$ sheathed wires with low grade amorphous boron powder, J. Supercond. Nov. Magn. 27 (2014) 497-504

[50] T.J.B. Holland and S.A.T. Redfern, Unit cell refinement from powder diffraction data: The use of regression diagnostics, Mineral. Mag., 61 (1997) 65-77.

[51] A.A. Nayeb-Hashemi and J.B. Clark, Cu-Mg (Copper - Magnesium), in T.B. Massalski, H. Okamoto, P.R. Subramanian and L. Kacprzak (Eds.), Binary Alloy Phase Diagrams Vol. 2 (1990) $1433-1435$ 
[52] A.A. Nayeb-Hashemi and J.B. Clark, Ir - Mg (Iridium - Magnesium) in T.B. Massalski, H.

Okamoto, P.R. Subramanian and L. Kacprzak (Eds.), Binary Alloy Phase Diagrams Vol. 3 (1990) $2325-2326$

[53] Y.G. Zhao, X.P. Zhang, P.T. Qiao, H.T. Zhang, S.L. Jia, B.S. Cao, M.H. Zhu, Z.H. Han, X.L. Wang and B.L. Gu, Influence of the starting composition $\operatorname{Mg}_{1-\mathrm{x}} \mathrm{B}_{2}$ on the structural and superconducting properties of the $\mathrm{MgB}_{2}$ phase, Physica C 366 (2001) 1 - 5

[54] D.G. Hinks, J.D. Jorgensen, H. Zheng and S. Short, Synthesis and stoichiometry of $\mathrm{MgB}_{2}$, Physica C 382 (2002) 166 - 176

[55] H. Xiao, W. Peng, W.H. Song, R.C. Ma, L. Zhang, J.J. Du and Y.P. Sun, Influence of Mg deficiency on the properties of $\mathrm{MgB}_{2}$, Physica C 386 (2003) $648-652$

[56] G.J. Xu, R. Pinholt, J. Bilde-Sørensen, J.C. Grivel, A.B. Abrahamsen and N.H. Andersen, Effect of starting composition and annealing temperature on irreversibility field and critical current density in $\mathrm{Mg}_{\mathrm{x}} \mathrm{B}_{2}$, Physica C 434 (2006) 67 - 70

[57] S.K. Chen. A. Serquis, G. Serrano, K. A. Yates, M.G. Blamire, D. Guthrie, J. Cooper, H. Wang, S. Margadonna and J. MacManus-Driscoll, Structural and superconducting property variations with nominal $\mathrm{Mg}$ non-stoichiometry in $\mathrm{Mg}_{\mathrm{x}} \mathrm{B}_{2}$ and its enhancement of upper critical field, Adv. Funct. Mater, 18 (2008) $113-120$

[58] N.D. Zhigadlo, S. Katrych, J. Karpinski, B. Batlogg, F. Bernardini, S. Massidda and R. Puzniak, Influence of $\mathrm{Mg}$ deficiency on crystal structure and superconducting properties in $\mathrm{MgB}_{2}$ single crystals, Phys. Rev. B 81 (2010) 054520

[59] T. Goto, K. Inagaki and K. Watanabe, Critical current density in filamentary (Nd, Sm, $\mathrm{Eu}, \mathrm{Gd})-\mathrm{Ba}-\mathrm{Cu}-\mathrm{O}$ superconductors prepared by a solution spinning method, Physica $\mathrm{C} 330$ (2000) $51-57$ 
[60] Y.-K. Kim, K. Chung, J. Yoo, I.-H. Song, J. Ko, W.-H. Chung, D.-H. Kim, X. Wang, S.X. Dou and P.-W. Shin, Effect of fine boron powders prepared with a self-propagating high temperature synthesis on flux pinning properties of the $\mathrm{MgB}_{2} / \mathrm{Fe}$ composite wires, J. Alloys Comp. 485 (2009) L44 - L46

[61] P. Badica, G. Aldica, M. Burdusel and K. Endo, Composites of $\mathrm{MgB}_{2}$ with $\mathrm{Bi}_{2} \mathrm{O}_{3}, \mathrm{Bi}$, $\mathrm{Sb}_{2} \mathrm{O}_{3}$, or Sb obtained by ex-situ spark plasma sintering, Jpn. J. Appl. Phys. 51(2012) 11PG13 [62] D. Batalu, G. Aldica, S. Popa, L. Miu, M. Enculescu, R.F. Negrea, I. Pasuk and P. Badica, High magnetic field enhancement of the critical current density by $\mathrm{Ge}, \mathrm{GeO}_{2}$ and $\mathrm{Ge}_{2} \mathrm{C}_{6} \mathrm{H}_{10} \mathrm{O}_{7}$ additions to $\mathrm{MgB}_{2}$, Scripta Materialia 82 (2014) $61-64$

[63] J. Huo, Y.C. Liu, Z.Z. Dong and H. Jiang, Effect of Sn-doping on the sintering process of $\mathrm{MgB}_{2}$ and its superconductive properties, J. Mater. Sci. Mater. Electron. 22 (2011) $233-237$

[64 ] M. Kuhberger and G. Gritzner, Effects of Sn, Co and Fe on $\mathrm{MgB}_{2}$, Physica C 370 (2002) 39 $-43$

[65] J.-C. Grivel, A. Abrahamsen and J. Bednarčik, Effects of $\mathrm{Cu}$ or Ag additions on the kinetics of $\mathrm{MgB}_{2}$ phase formation in Fe-sheathed wires, Supercond. Sci. Technol. 21 (2008) 035006 [66] J.-C. Grivel, N.H. Andersen, P.G.A.P. Pallewatta, Y. Zhao and M.v. Zimmermann, Influence of $\mathrm{Bi}, \mathrm{Se}$ and $\mathrm{Te}$ additions on the formation temperature of $\mathrm{MgB}_{2}$, Supercond. Sci. Technol. 25 (2012) 015010 


\section{Figure captions}

Figure 1: XRD patterns of the powders mechanically extracted from the wires after annealing at $700^{\circ} \mathrm{C}, 800^{\circ} \mathrm{C}$ or $900^{\circ} \mathrm{C}$. The reflections with Miller indices originate from $\mathrm{MgB}_{2}, \bullet \mathrm{Mg}, \mathrm{O}$ Boron. The $\mathrm{x}$ value refers to the amount of $\mathrm{Ir}$ in the nominal composition $\mathrm{Mg}_{1-\mathrm{x}} \mathrm{Ir}_{\mathrm{x}} \mathrm{B}_{2.04}$.

Figure 2: SEM images (backscattering mode) of polished cross-sections of samples after reaction at $700^{\circ} \mathrm{C}$ (a), (b) and (c), $800^{\circ} \mathrm{C}$ (d), (e) and (f) or $900^{\circ} \mathrm{C}(\mathrm{g})$, (h) and (i) with $\mathrm{Mg}_{1-}$ ${ }_{x} \operatorname{Ir}_{x} B_{2.04}$ nominal compositions (x = 0.00 (a), (d) and (g) $0.01(\mathrm{~b}),(\mathrm{e})$ and (h), 0.02 (c), (f) and (i).

Figure 3: SEM image (backscattering mode) of the sample with $M g_{0.98} \mathrm{Ir}_{0.02} \mathrm{~B}_{2.04}$ nominal stoichiometry after reaction at $800^{\circ} \mathrm{C}$ (a) and EDS elemental maps showing the relative concentrations of $\mathrm{Mg}(\mathrm{b}), \mathrm{B}(\mathrm{c})$ and $\mathrm{Ir}(\mathrm{d})$. The numbers in Fig.3a refer to B-rich magnesium borides: "7" $=\mathrm{MgB}_{7}$ and " $12 "=\mathrm{MgB}_{12}$.

Figure 4: Critical temperature $\left(\mathrm{T}_{\mathrm{c}}\right)$ versus nominal composition for the samples reacted at various temperatures. The inset shows three typical transition curves.

Figure 5: Double logarithmic plots of the normalized critical current density $\left(j_{c}\right)$ versus applied field (B) at various temperatures for the samples without Ir and with 2 at.\% Ir substitution for $\mathrm{Mg}$, both reacted at $800^{\circ} \mathrm{C}$. The insets show the magnetization hysteresis loops used for calculating the $\mathrm{j}_{\mathrm{c}}$ values.

Figure 6: Critical current density $\left(\mathrm{j}_{\mathrm{c}}\right)$ values versus applied field (B) for all samples at $30 \mathrm{~K}$ (a) and $10 \mathrm{~K}(\mathrm{~b})$.

Figure 7: Normalised pinning force plots for $10 \mathrm{~K}$ and $30 \mathrm{~K}$ for all samples as well as theoretical curves calculated on the basis of different flux pinning mechanisms.

\section{Table caption}


Table 1: a and c lattice parameters, critical temperature $\left(\mathrm{T}_{\mathrm{c}}\right)$ and accommodation field $\left(\mathrm{B}^{*}\right)$ for all samples. The $\mathrm{T}_{\mathrm{c}}$ and $\mathrm{B}^{*}$ values have uncertainties of $0.15 \mathrm{~K}$ and $1 \%$ respectively.

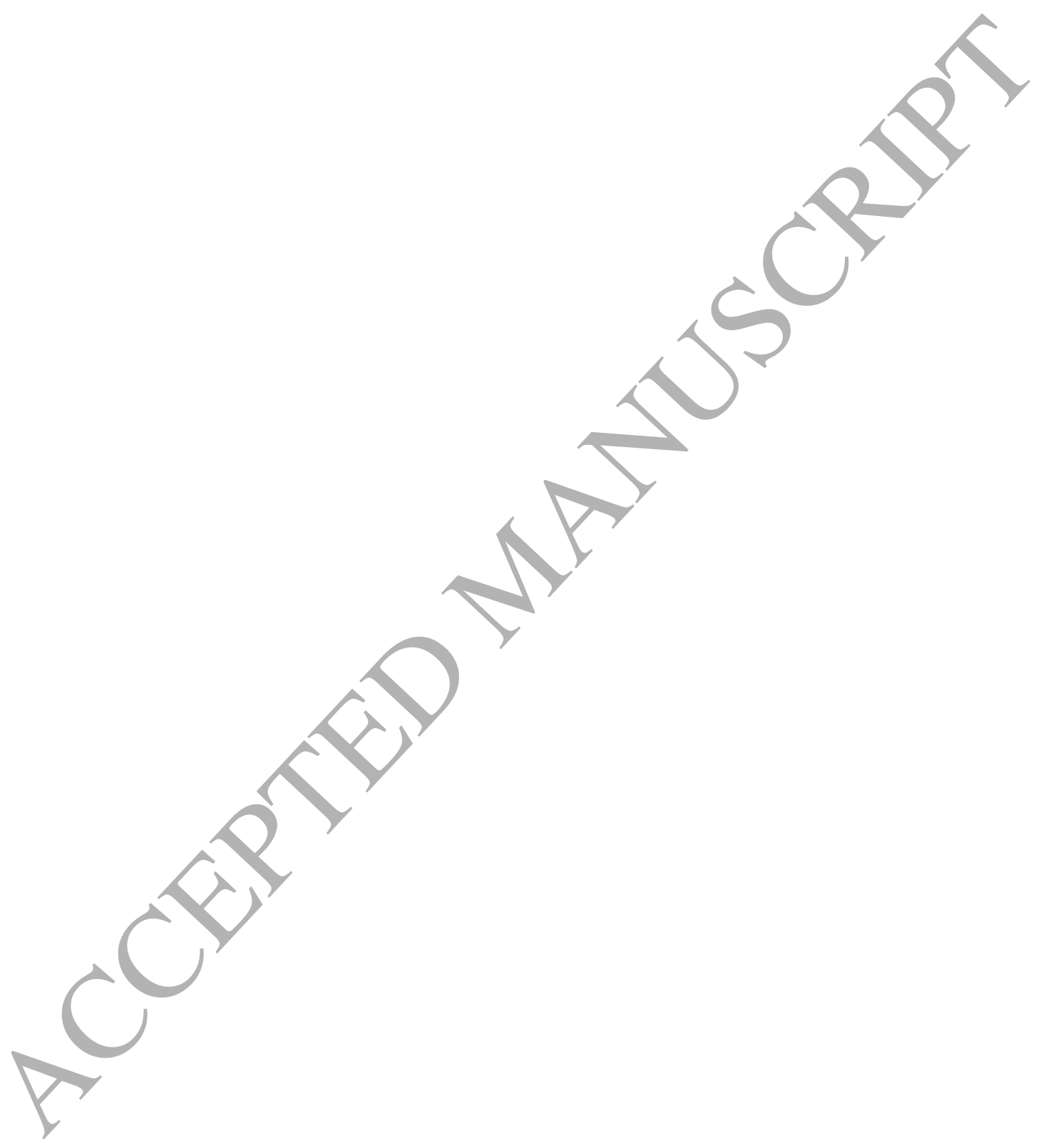




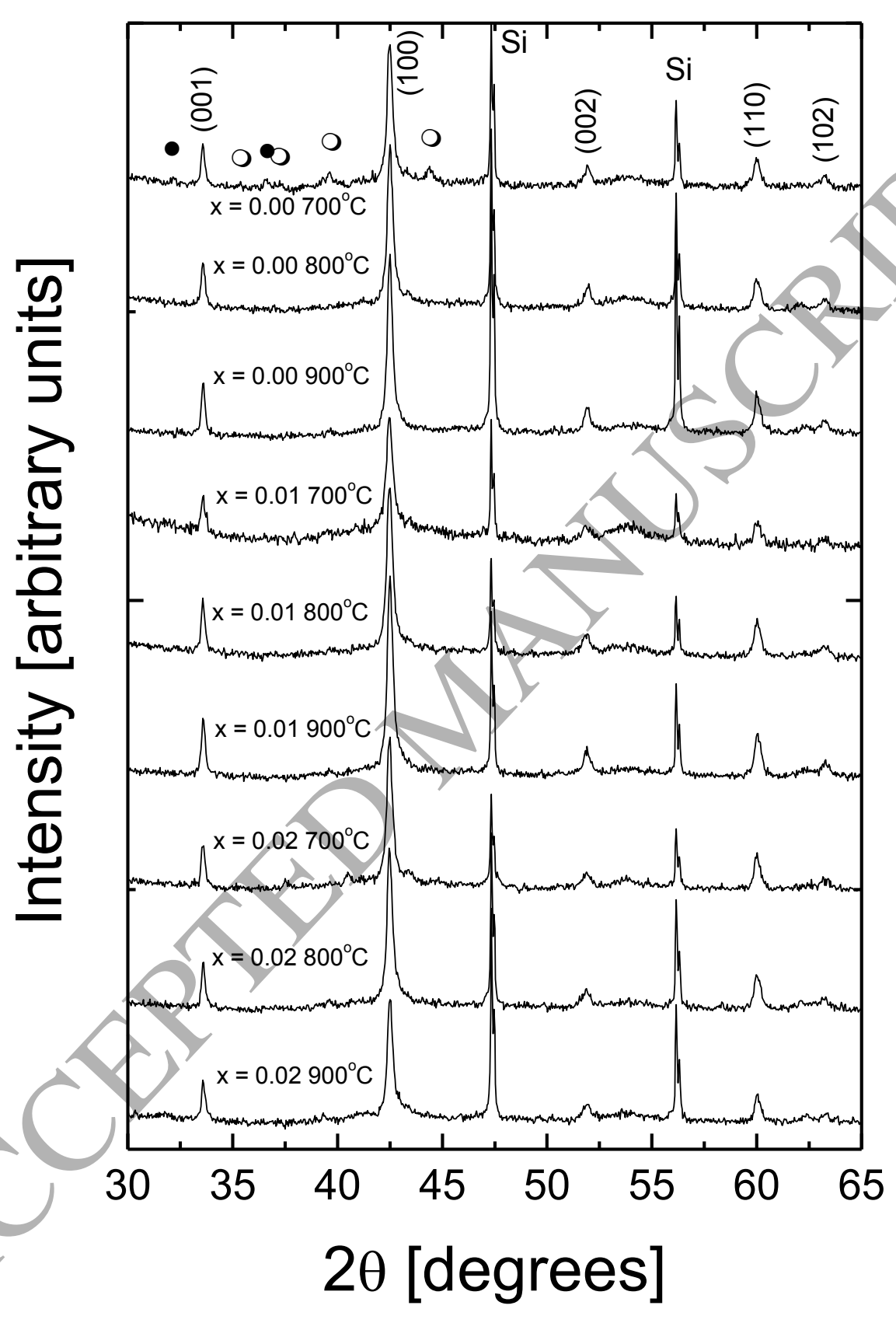

Figure 1 

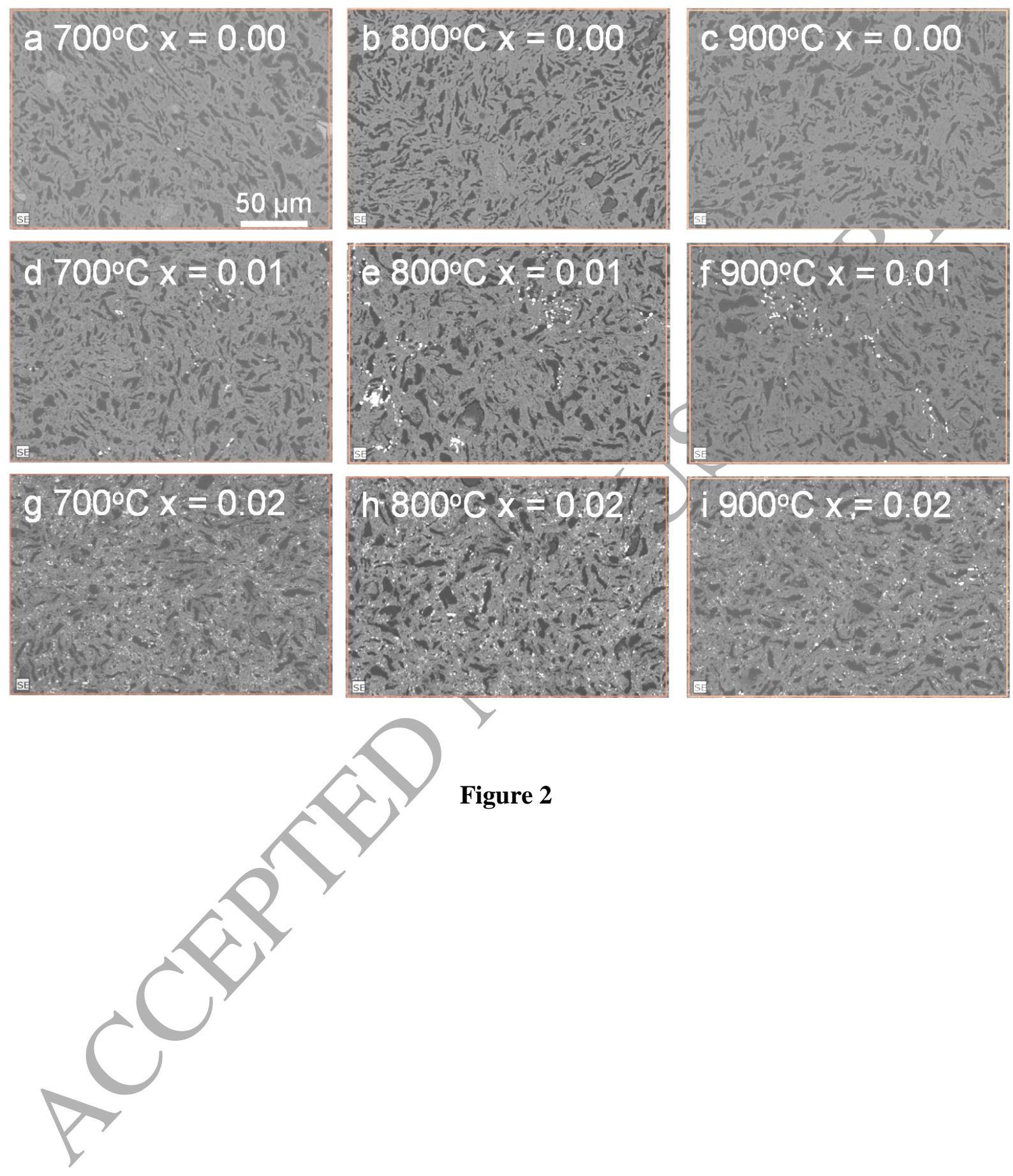

Figure 2 

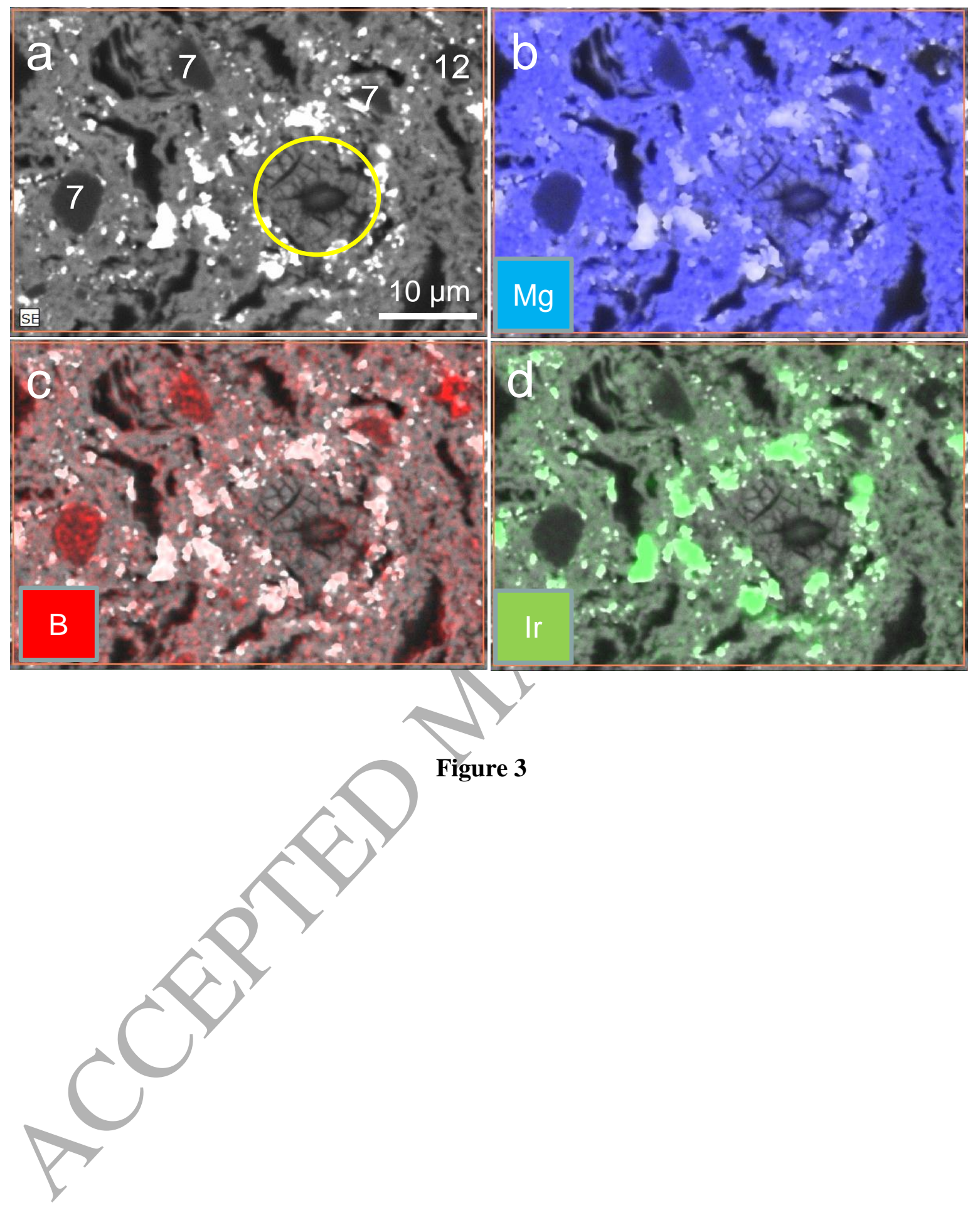

Figure 3 


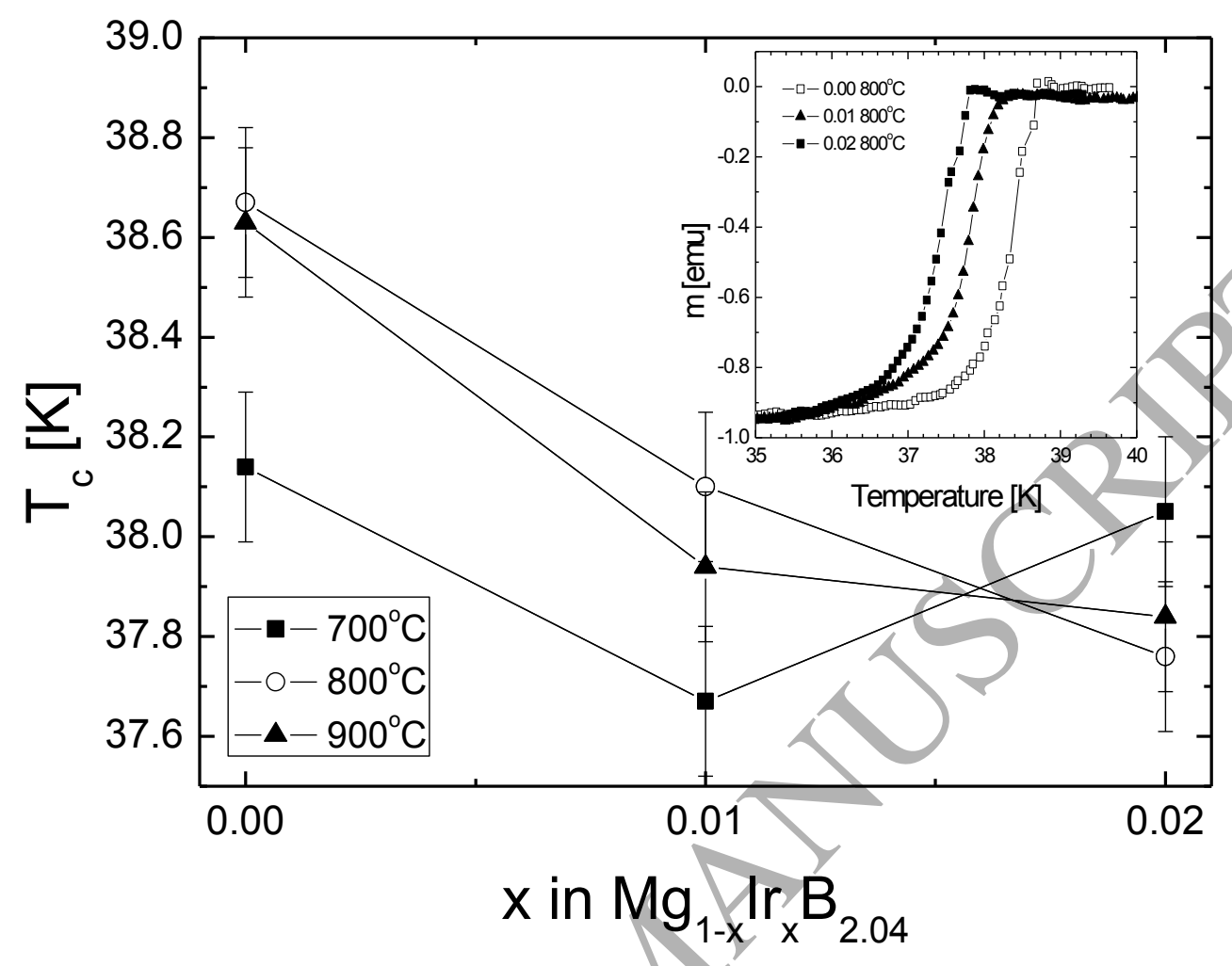

Figure 4 


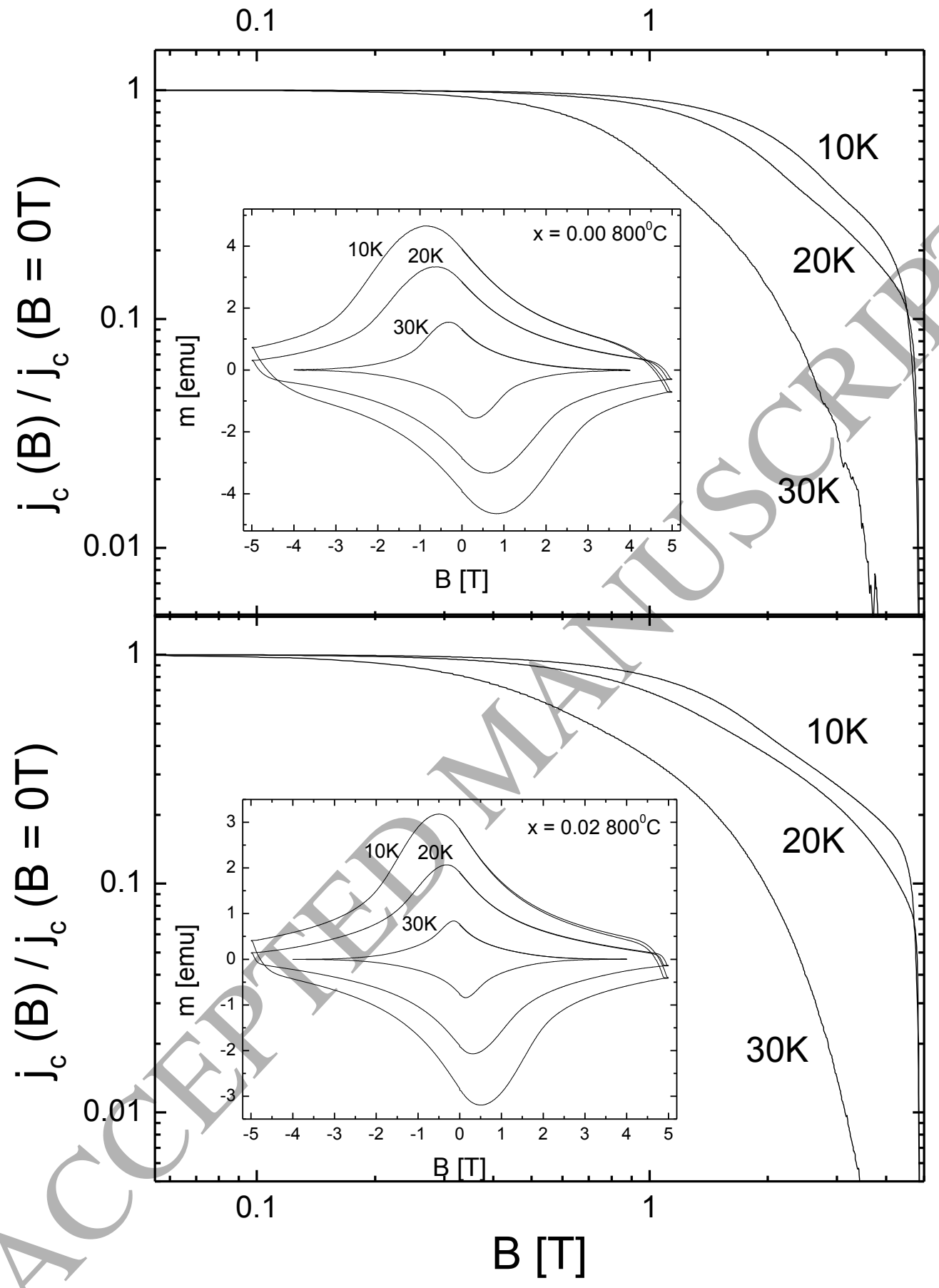

Figure 5 

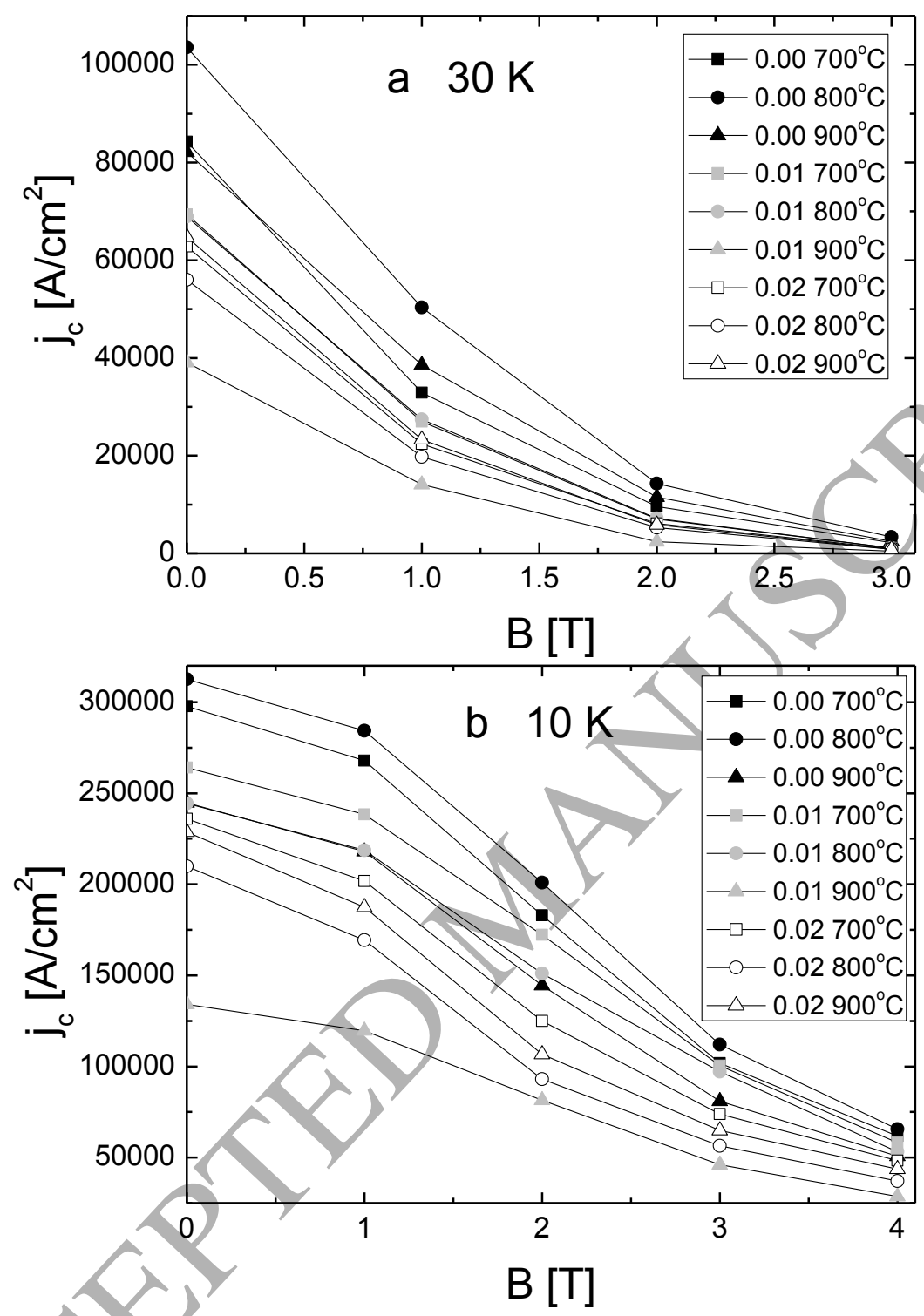

Figure 6 


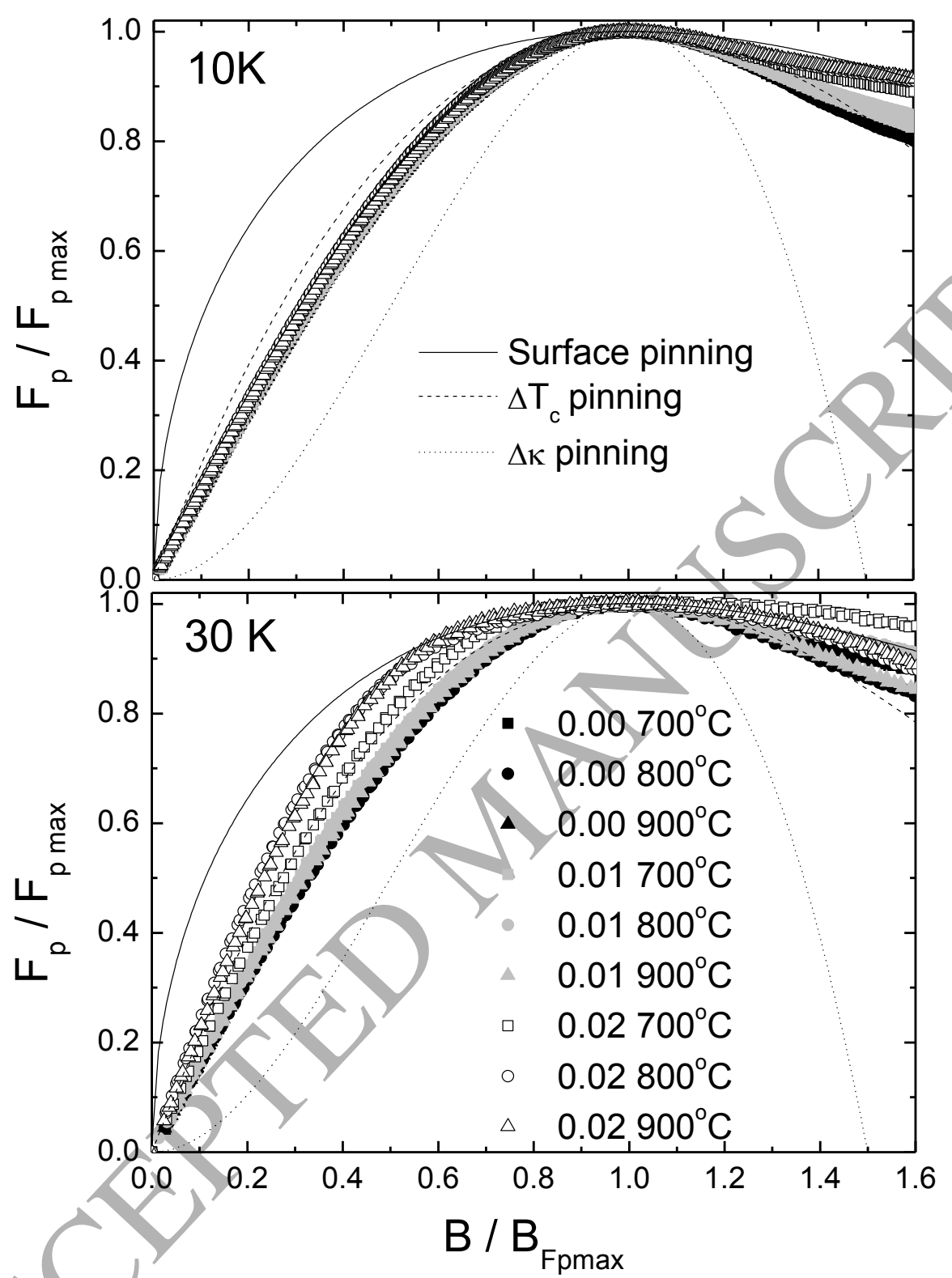

Figure 7 


\begin{tabular}{|c|c|c|c|c|c|c|c|}
\hline$x^{1}$ & $\mathrm{~T}_{\text {react }}\left[{ }^{\circ} \mathrm{C}\right]$ & $\mathrm{a}[\AA ̊]$ & $c[\AA]$ & $\mathrm{T}_{\mathrm{c}}[\mathrm{K}]$ & $\mathrm{B}^{*}{ }_{30 \mathrm{~K}}[\mathrm{mT}]$ & $\mathrm{B}^{*}{ }_{20 \mathrm{~K}}[\mathrm{mT}]$ & $10 \mathrm{~K}[\mathrm{mT}]$ \\
\hline 0.00 & 700 & $3.0829(4)$ & $3.5223(5)$ & 38.14 & 342 & & 5 \\
\hline 0.01 & 700 & $3.0823(11)$ & $3.5232(14)$ & 37.67 & 308 & & 1005 \\
\hline 0.02 & 700 & $3.0823(11)$ & $3.5220(13)$ & 38.05 & 265 & & 810 \\
\hline 0.00 & 800 & $3.0824(2)$ & $3.5203(3)$ & 38.67 & & 811 & 1045 \\
\hline 0.01 & 800 & $3.0816(6)$ & $3.5233(8)$ & & 327 & 711 & 973 \\
\hline 0.02 & 800 & $3.0814(3)$ & $3.5251(3)$ & & 228 & 491 & 691 \\
\hline 0.00 & 900 & $3.0822(4)$ & $3.5218(5)$ & 38.63 & 390 & 742 & 950 \\
\hline 0.01 & 900 & 3.0814 & $217(9)$ & 37.94 & 324 & 705 & 968 \\
\hline 0.02 & 900 & 3.082 & $5222(5)$ & 37.84 & 258 & 530 & 719 \\
\hline
\end{tabular}

${ }^{1}$ in $\mathrm{Mg}_{1-\mathrm{x}} \mathrm{Ir}_{\mathrm{x}} \mathrm{B}_{2.04}$ 